\title{
Major Depression and Stigma among Individuals with Multidrug-Resistant Tuberculosis in South Africa
}

\author{
Thirusha Naidu, ${ }^{1 \star}$ Suntosh R. Pillay, ${ }^{2,7}$ Suvira Ramlall, ${ }^{2}$ Sbusisiwe Sandra Mthembu, ${ }^{3}$ Nesri Padayatchi, ${ }^{4}$ Jonathan K. Burns, ${ }^{2,5}$ \\ and Andrew Tomita ${ }^{6,8}$ \\ ${ }^{1}$ Behavioural Medicine, University of KwaZulu-Natal, Durban, South Africa; ${ }^{2}$ Department of Psychiatry, University of KwaZulu-Natal, Durban, South \\ Africa; ${ }^{3}$ South African Medical Research Council, Durban, South Africa; ${ }^{4} \mathrm{MRC}$ HIV-TB Pathogenesis and Treatment Research Unit, Centre for the \\ AIDS Programme of Research in South Africa, Durban, South Africa; ${ }^{5}$ Institute of Health Research, University of Exeter, Exeter, United Kingdom; \\ ${ }^{6}$ Centre for Rural Health, University of KwaZulu-Natal, Durban, South Africa; ${ }^{7}$ King DinuZulu Hospital, KwaZulu-Natal Department of Health, \\ Durban, South Africa; ${ }^{8}$ KwaZulu-Natal Research Innovation and Sequencing Platform (KRISP), College of Health Sciences, University of \\ KwaZulu-Natal, Durban, South Africa
}

\begin{abstract}
Stigma is an important social determinant of health-seeking behavior; however, the nature and extent of its association with depression among people living with multidrug-resistant tuberculosis (MDR-TB) are not wellunderstood. We enrolled 200 microbiologically confirmed MDR-TB inpatients at a TB specialist hospital in KwaZulu-Natal Province, an area considered the epicenter for MDR-TB coinfection in South Africa. Four aspects of stigma and their association with major depression were assessed through individual interviews: 1) community and 2) patient perspectives toward TB, and 3) community and 4) patient perspectives toward HIV. A major depressive episode (MDE), HIV coinfection, and low income were significantly associated with greater stigma subscales. Based on an adjusted regression model, the MDE was the only factor independently associated with (all aspects of) stigma. These results indicate the potential utility of addressing stigma associated with the MDE as an important step in improving health-seeking behavior to promote adherence and retention in care.
\end{abstract}

\section{INTRODUCTION}

Tuberculosis (TB) is a global emergency that is responsible for 1.5 million deaths annually, with most cases occurring in sub-Saharan Africa (SSA). ${ }^{1}$ Tuberculosis remains the leading cause of mortality among people living with HIV in South Africa, ${ }^{2}$ which is also at the forefront of the TB and HIV syndemic, where more than half of TB patients (56.7\%) were living with HIV coinfection in $2015 .^{3}$ Despite the availability of TB treatment, community-wide approaches to control have not been implemented at scale, ${ }^{4}$ and the rapid investment in HIV treatment scale-up has failed to materialize in reversing the coinfections. The recent large treatment as prevention (TasP) trial that enrolled 28,000 participants in rural KwaZulu-Natal (KZN) failed, as a public health intervention, to reduce HIV incidence. ${ }^{5}$ Despite their proximity to clinics and access to antiretroviral treatments (ARTs), less than half the TaSP participants living with HIV adhered to their treatment. It has been argued that an exclusively public health approach fails to account for the real-world social complexities of accessing health care. It also underscores the danger of an overly biomedical approach ${ }^{6}$ that disregards social constraints, such as stigma, $^{7}$ thereby impeding optimal treatment outcomes. ${ }^{8-10}$

Decades of investigation suggest that TB-related stigma is a persistent phenomenon that has serious repercussions for the ways people seek care, ${ }^{11}$ initiate ${ }^{12}$ and adhere to treatment. ${ }^{13}$ The extent of stigma associated with TB and TB/HIV coinfection $^{14-16}$ has been documented in resource-limited nations, including Ethiopia, ${ }^{17}$ Gambia, $^{18}$ Ghana, $^{19}$ India, ${ }^{20}$ Mexico, ${ }^{21}$ Nepal, $^{22,23}$ Pakistan $^{24}$ and Uzbekistan. ${ }^{25}$

Compounding the complex national challenge of the TB epidemic is the persistence of multidrug-resistant tuberculosis

*Address correspondence to Thirusha Naidu, Department of Behavioural Medicine, Room 301, 3rd Floor, George Campbell Building, North Entrance, Rick Taylor Road, Howard College Campus, University of KwaZulu-Natal, Durban 4041, South Africa. E-mail: naidut10@ukzn.ac.za
(MDR-TB), being mainly due to the transmission of already resistant strains in South Africa. ${ }^{26}$ Multidrug-resistant tuberculosis develops as a result of the incorrect use of antimicrobial drugs or through contact with a person infected with the bacilli. MDR-TB is a difficult disease to treat, requiring an onerous care regime that is characterized by a high pill burden, toxic medication, frequent or extended hospitalizations, and social isolation, creating ideal conditions for stigmatization. According to a metaanalysis, ${ }^{27}$ the mortality rate among the MDR-TB and HIV coinfection group was estimated to be nearly one-third (30.9\%).

The adverse impact of stigma on health-seeking behavior can be exacerbated by mental illness, with only $25 \%$ of individuals with mental disorders having sought treatment within a 12month period in South Africa. ${ }^{28}$ People with mental illness are reluctant to seek professional assistance, ${ }^{29}$ despite experiencing major depression, with a lifetime prevalence of $9.8 \%,{ }^{30}$ being one of the most pervasive mental illnesses in South Africa. Depression is one of the most common mental health disorders of individuals living with $\mathrm{HIV}^{31}$ its comorbidity with TB and HIV being well-established. A community-based study from 48 lowand middle-income countries suggested that depression affects approximately one-quarter $(23.7 \%)$ of all individuals with TB. ${ }^{32}$

KwaZulu-Natal (KZN) Province in South Africa, the area of interest in the current investigation, is regarded as the epicenter for South Africa's MDR-TB infection. ${ }^{33-35}$ While KZN has the highest prevalence of patients with MDR-TB in the country, ${ }^{36}$ there is no research, to our knowledge, on the associated stigma (and the role of depression), with exception of one qualitative study that highlights the important social constraints to treatment and care. $^{37}$ This study aimed to address this gap in evidence by investigating the nature and extent of the association between stigma and depression among people living with MDR-TB.

\section{METHODS}

Study design and participants. We prospectively enrolled consecutive inpatients with culture-confirmed MDR-TB who 
were admitted to a referral-based TB specialist hospital in KZN from September 2015 through October 2016. The inclusion criteria were consenting isiZulu (or English)-speaking individuals, aged 21-59 years, with no history of inpatient/outpatient admission, or past receipt of MDR-TB standard of care outside that study site. Individuals with developmental disability or without primary school-level education were excluded due to the nature of the study assessment. Participants were provided with a description of the study, and written informed consent (and a separate consent section for accessing medical records) was obtained. The University of KZN Biomedical Research Ethics Committee approved the study.

Primary exposure and outcome. The primary exposure of interest was depression, with the Mini International Neuropsychiatric Interview v6.0, ${ }^{38}$ a structured diagnostic schedule based on Diagnostic and Statistical Manual of Mental Disorders-IV, being used to identify the most recent (i.e. current) major depressive episode (MDE). The primary outcome (e.g. dependent variable) was stigma, which was measured using the TB and HIV stigma (THS) scales. The scales were previously validated to measure the psychological and social constructs of stigma associated with TB and HIV at both community and individual levels in developing county settings, ${ }^{14}$ and capture external stigma: the experience of discriminatory treatment by others. ${ }^{39}$ The THS consists of four subscales that measured 1) community perspectives toward TB (11 items), 2) patient perspectives toward TB (12 items), 3) community perspectives toward HIV (11 items), and 4) patient perspectives toward HIV (10 items). Each subscale consisted of a four-point Likert scale scored on the response categories: (0) strongly disagree, (1) disagree, (2) agree, and (3) strongly agree. All the items were phrased in third person (i.e. some people) to measure external stigma as perceived by the study participants, which allows them to respond irrespective of their HIV status. All the item responses on each subscale were added together to create the summary score and standardized to a 50-point scale. A higher standardized score indicates a higher stigma, with the Cronbach alpha for community and patient perspectives toward TB being 0.83 and 0.85 , respectively, whereas for HIV, it was 0.90 and 0.88 , respectively.

Information on clinical background and socio-demographic factors, such as gender, age, race/ethnicity, marital status, educational attainment and income were collected in face-toface interviews. The HIV status of the inpatients was obtained from the National Health Laboratory Service database situated at the study site. All study instruments were translated from English to isiZulu (local language of $K Z N$ ) by a firstlanguage isiZulu-speaking clinical psychologist who was familiar with the context. Another first-language isiZuluspeaking clinical psychologist, who was also familiar with the context, back-translated the tool into English. The two translators then rechecked and corroborated on discrepancies for the final version. The tool was administered by a third first-language isiZulu-speaking clinical psychologist who confirmed the face validity of the isiZulu version and its utility in the context.

Data analysis. Descriptive statistics were used to summarize the socio-demographic and clinical data information and the THS scale. The socio-demographic and clinical characteristics were summarized using means \pm SD for continuous variables (e.g. pain scale) and as proportions (\%) for categorical variables. Thereafter, we fitted unadjusted (bivariate) and adjusted (multiple) regression models to identify the socio-demographic, clinical risk and protective correlates of stigma (subscales 1-4). All statistical analyses were performed using STATA 15.

\section{RESULTS}

Summary of sociodemographic characteristics. Of the 200 study participants, the majority were female $(n=161$; $80.50 \%$ ), black ( $n=196 ; 98.00 \%)$, earning $\leq$ R1000 (\$78) per month ( $n=119 ; 59.50 \%$ ), and had not completed secondarylevel education ( $n=109 ; 54.50 \%)$. Ten percent $(n=20)$ were engaged in casual intimate partnerships (i.e. intimate partner relationship)

TABLE 1

Sociodemographic and clinical characteristics of MDR-TB study participants $(n=200)$

\begin{tabular}{|c|c|c|c|c|c|c|c|}
\hline \multirow[b]{2}{*}{ Variable } & \multirow[b]{2}{*}{ Categories } & \multicolumn{2}{|c|}{ Total } & \multicolumn{2}{|c|}{ With MDE } & \multicolumn{2}{|c|}{ Without MDE } \\
\hline & & $n$ & $\%$ & $N$ & $\%$ & $N$ & $\%$ \\
\hline \multirow[t]{2}{*}{ Gender } & Female & 161 & 80.5 & 18 & 85.7 & 143 & 79.9 \\
\hline & Male & 39 & 19.5 & 3 & 14.3 & 36 & 20.1 \\
\hline \multirow[t]{3}{*}{ Age category (years) } & $21-29$ & 65 & 32.5 & 7 & 33.3 & 58 & 32.4 \\
\hline & 30-39 & 87 & 43.5 & 11 & 52.4 & 76 & 42.5 \\
\hline & $40-55$ & 48 & 24.0 & 3 & 14.3 & 45 & 25.1 \\
\hline \multirow[t]{2}{*}{ Race/ethnicity } & Black & 196 & 98.0 & 20 & 95.2 & 176 & 98.3 \\
\hline & Colored/Indian & 4 & 2.0 & 1 & 4.8 & 3 & 1.7 \\
\hline \multirow[t]{2}{*}{ Education } & $<$ Grade 12 & 109 & 54.5 & 13 & 61.9 & 96 & 53.6 \\
\hline & $\geq$ Grade 12 & 91 & 45.5 & 8 & 38.1 & 83 & 46.4 \\
\hline \multirow[t]{3}{*}{ Marital status } & Married/stable partnership & 113 & 56.5 & 12 & 57.1 & 101 & 56.4 \\
\hline & Casual partnership & 20 & 10.0 & 3 & 14.3 & 17 & 9.5 \\
\hline & No relationship/partnership & 67 & 33.5 & 6 & 28.6 & 61 & 34.1 \\
\hline \multirow[t]{3}{*}{ Income per month } & $\leq \mathrm{R} 1000$ & 119 & 59.5 & 14 & 66.7 & 105 & 58.7 \\
\hline & R1001-R5000 & 58 & 29.0 & 6 & 28.6 & 52 & 29.1 \\
\hline & $\geq \mathrm{R} 5001$ & 23 & 11.5 & 1 & 4.8 & 22 & 12.3 \\
\hline \multirow[t]{2}{*}{ Infection status } & MDR-TB (i.e., mono-infection) & 21 & 10.5 & 3 & 14.3 & 18 & 10.1 \\
\hline & MDR-TB and HIV+ (i.e., coinfection) & 179 & 89.5 & 18 & 85.7 & 161 & 89.9 \\
\hline \multirow[t]{2}{*}{ Major depressive episode (MDE) } & No & 179 & 89.5 & - & - & - & - \\
\hline & Yes & 21 & 10.5 & - & - & - & - \\
\hline
\end{tabular}

$\mathrm{MDE}=$ major depressive episode MDR-TB = multidrug-resistant tuberculosis 
TABLE 2

Stigma subscale scores and their comparison with original TB sample population

\begin{tabular}{|c|c|c|c|}
\hline & Subscale & Mean score & SD \\
\hline \multicolumn{4}{|l|}{ TB social stigma scale } \\
\hline Community perspectives toward TB & 1 & 37.58 & 5.97 \\
\hline Patient perspectives toward TB & 2 & 38.08 & 5.98 \\
\hline \multicolumn{4}{|l|}{ HIV social stigma scale } \\
\hline Community perspectives toward HIV* & 3 & 34.97 & 7.28 \\
\hline Patient perspectives toward HIV & 4 & 39.44 & 6.42 \\
\hline
\end{tabular}

Summary of clinical characteristics and stigma. Most participants were $(n=179 ; 89.50 \%)$ also living with HIV. Table 1 shows that $10.50 \%(n=21)$ were diagnosed with an MDE, and the summary stigma scores based on the 50-point scale are provided in Table 2.

Association between depression and stigma. The results of both the bivariate regression analyses (Table 3) indicate that individuals with an MDE scored significantly higher across all four subscales than those without. In addition, higher stigma scores were observed in HIV coinfection $(\beta=2.72, P<0.05)$ in subscale 2 (patient perspectives toward TB), low income $(\beta=$ $4.10, P=0.05$ ) in subscale 3 (community perspectives toward HIV), and subscale $4(\beta=3.20, P=0.03$ ) (patients' perspectives toward HIV). No sociodemographic or clinical covariate was associated with subscale 1 . When the adjusted regression models were fitted, individuals with an MDE reported significantly greater stigma across all four subscales: subscale 1 (adj $\beta=3.36, P=0.02)$, subscale $2(\operatorname{adj} \beta=3.89, P<0.01)$, subscale $3(\operatorname{adj} \beta=4.24, P=0.01)$, and subscale $4(\operatorname{adj} \beta=3.41, P=0.03)$.

\section{DISCUSSION}

This study investigated the extent and association between stigma and depression in the rarely examined group of MDR-
TB patients whose profiles reflect socially and economically disadvantaged backgrounds (e.g. lower education and economically challenged). We found that individuals with an MDE scored significantly higher across all four stigma subscales than those without.

No studies have been published that examine the link between major depression, HIV, and stigma that are generalizable for MDR-TB sample populations, making comparisons challenging. When comparing the findings with those of the original study of the TB population (but not MDR-TB) for which the THS was designed, our study participants scored significantly higher on stigma in all four THS subscales. ${ }^{14}$ In addition, a number of studies originating in other SSA countries (Ethiopia and Lesotho, but among TB only sample participants) found significant relationships between depression and stigma. ${ }^{17,40,41}$

A sense of hopelessness is a characterizing feature of depression, which makes people more susceptible to viewing the world and the behavior of others negatively. People with depression are more likely to make negative attributions to events and experiences, thus increasing their perception of stigma. Our study observed greater stigma scores in participants with HIV coinfection and MDE in subscale 2 (patient perspectives toward TB). Despite ARTs having made HIV a manageable condition, ${ }^{42,43}$ HIV infection remains a risk factor for perceived stigma (based on bivariate results) for individuals with low income. Individuals with MDR-TB often face difficult socioeconomic circumstances, such as food insecurity, ${ }^{44}$ consistent with the contention that the effects of existing social inequalities exacerbate disease-related stigma. ${ }^{45}$ However, the effect of socio-economic status is diminished in the adjusted regression models. Although MDR-TB is a life-threatening, easily communicable and difficult-to-treat condition, our regression, based on an adjusted regression model, may add credence to the serious nature of depression in MDR-TB that leads to stigma.

The current study was conducted in an inpatient treatment setting, with the results therefore not being generalizable to community settings. A community-based TB treatment

TABLE 3

Multivariate regression results to identify sociodemographic and clinical covariates related to stigma

\begin{tabular}{|c|c|c|c|c|c|c|c|c|c|c|c|c|c|}
\hline & & \multicolumn{3}{|c|}{ Subscale 1} & \multicolumn{3}{|c|}{ Subscale 2} & \multicolumn{3}{|c|}{ Subscale 3} & \multicolumn{3}{|c|}{ Subscale 4} \\
\hline & & $\beta$ & $\operatorname{adj} \beta$ & SE & $\beta$ & $\operatorname{adj} \beta$ & SE & $\beta$ & $\operatorname{adj} \beta$ & SE & $\beta$ & $\operatorname{adj} \beta$ & SE \\
\hline \multirow[t]{2}{*}{ Gender } & Male & & & & & & & & & & & & \\
\hline & Female & 1.51 & 0.93 & 1.11 & 2.07 & 1.2 & 1.08 & 1.19 & 0.56 & 1.32 & 1.20 & 0.67 & 1.18 \\
\hline \multirow[t]{3}{*}{ Age category (years) } & $21-29$ & & & & & & & & & & & & \\
\hline & $30-39$ & 0.18 & 0.27 & 1.05 & 0.89 & 0.89 & 1.02 & 0.97 & 1.76 & 1.25 & 0.54 & 1.22 & 1.11 \\
\hline & $40+$ & -1.17 & -0.91 & 1.29 & -0.60 & -0.48 & 1.25 & -1.73 & 0.18 & 1.53 & -1.06 & 0.53 & 1.37 \\
\hline \multirow[t]{3}{*}{ Marital status } & No relationship/partner & & & & & & & & & & & & \\
\hline & Married/stable partner & -0.17 & -0.31 & 1.48 & -1.76 & -1.77 & 1.43 & 2.26 & 1.95 & 1.76 & -0.12 & -0.4 & 1.57 \\
\hline & Casual partner & 0.46 & 0.42 & 0.96 & 1.77 & $1.89^{\star}$ & 0.93 & 0.33 & 0.32 & 1.15 & -0.26 & -0.37 & 1.02 \\
\hline \multirow[t]{2}{*}{ Education } & $<$ Grade 12 & & & & & & & & & & & & \\
\hline & $\begin{array}{l}\geq \text { Grade } 12 \\
\text { R1001-R5000 }\end{array}$ & -0.93 & -0.87 & 0.97 & -1.24 & -1.29 & 0.94 & -1.24 & -0.09 & 1.16 & -0.79 & 0.32 & 1.03 \\
\hline \multirow{2}{*}{ Income } & $\leq \mathrm{R} 1000$ & 1.06 & -0.38 & 1.62 & 1.39 & 0.05 & 1.57 & $4.10^{\star}$ & 3.03 & 1.93 & $3.20^{*}$ & 3.02 & 1.72 \\
\hline & $\geq \mathrm{R} 5001$ & -0.49 & -1.62 & 1.61 & 0.18 & -0.91 & 1.56 & 1.32 & 0.07 & 1.92 & 0.47 & 0.06 & 1.71 \\
\hline \multirow[t]{2}{*}{ Infection status } & MDR-TB and HIV- & & & & & & & & & & & & \\
\hline & $\begin{array}{l}\text { MDR-TB and HIV+ } \\
\text { No }\end{array}$ & 1.85 & 1.58 & 1.45 & $2.72^{\star}$ & 1.73 & 1.4 & 2.40 & 2.01 & 1.73 & 1.32 & 1.14 & 1.54 \\
\hline MDE & Yes & $3.53^{*}$ & $3.36^{*}$ & 1.41 & $3.99^{\star \star}$ & $3.89^{\star \star}$ & 1.37 & $4.75^{\star \star}$ & $4.24^{\star}$ & 1.68 & $3.77^{\star}$ & $3.41^{*}$ & 1.50 \\
\hline
\end{tabular}

$\mathrm{MDE}=$ major depressive episode; MDR-TB = multidrug-resistant tuberculosis; $\mathrm{TB}$ = tuberculosis

${ }^{*} P<0.01,{ }^{\star} P<0.05$. Subscale $1=$ community perspectives toward TB; subscale 2 = patient perspectives toward TB; subscale $3=$ community perspectives toward $\mathrm{HIV}$; subscale $4=$ patient perspectives toward HIV. 
strategy in a generalized HIV-epidemic setting requires a better understanding of the extent of stigma in patients with MDR-TB once they are discharged from inpatient treatment. In addition, the THS subscales do not take the role of internal stigma into consideration. To our knowledge, no research has been conducted on stigma and its link to major depression in the MDR-TB population in SSA. Our study highlights the importance of addressing mental disorders, particularly depression, and the possible influence of individual and community stigma as an essential step toward early linkage to and retention of care for MDR-TB patients in South Africa. ${ }^{46}$ Notwithstanding these limitations, this study pointed to the need for further investigation into the association between stigma and depression in persons with MDR-TB.

Received June 4, 2019. Accepted for publication April 4, 2020.

Published online July 20, 2020.

Financial support: AT was supported by SA MRC Flagship grant (MRC-RFAUFSP-01-2013/UKZN HIVEPI). Data collection of the study was supported by National Institutes of Health Research Training Grant (R25TW009337), funded by the Fogarty International Center and the National Institute of Mental Health.

Disclosure: The Biomedical Research Ethics Committee of the University of KwaZulu-Natal (BREC) Durban, South Africa, gave full ethics approval for this study. The approval number is BF251/14. Written informed consent was obtained from study participants.

Disclaimer: The content is solely the responsibility of the authors and does not necessarily represent the official views of the SA MRC, or the NIH.

Authors' addresses: Thirusha Naidu, Behavioural Medicine, University of KwaZulu-Natal, Durban, South Africa, E-mail: naidut10@ ukzn.ac.za. Suntosh Pillay and Suvira Ramlall, Department of Psychiatry, University of KwaZulu-Natal, Durban, South Africa, E-mails: suntosh.pillay@kznhealth.gov.za and ramlalls4@ukzn.ac.za. Sbusisiwe Sandra Mthembu, South African Medical Research Council, Durban, South Africa, E-mail: sbusimthembu@gmail.com. Nesri Padayatchi, MRC HIV-TB Pathogenesis and Treatment Research Unit, Centre for the AIDS Programme of Research in South Africa, Durban, South Africa, E-mail: nesri.padayatchi@caprisa.org. Jonathan Burns, Institute of Health Research, University of Exeter, Exeter, United Kingdom, E-mail: j.burns@exeter.ac.uk. Andrew Tomita, Centre for Rural Health, University of KwaZulu-Natal, Durban, South Africa, E-mail: tomita@ukzn.ac.za.

\section{REFERENCES}

1. Zumla A, Schito M, Chakaya J, Marais B, Mwaba P, Migliori GB, Hoelscher M, Maeurer M, Wallis RS, 2016. World TB day 2016: reflections on the global TB emergency. Lancet Respir Med 4: 249-251.

2. Statistics South Africa, 2016. Mortality and Causes of Death in South Africa: Findings from Death Notification. Available at: https://www.statssa.gov.za/publications/P03093/P030932016.pdf.

3. Massyn N, Peer N, English R, Padarath A, Barron P, Day C, 2016. District Health Barometer 2015/16. Durban, South Africa: Health Systems Trust.

4. Ayles $\mathrm{H}$ et al., 2013. Effect of household and community interventions on the burden of tuberculosis in southern Africa: the ZAMSTAR community-randomised trial. Lancet 382: 1183-1194.

5. Iwuji CC et al., 2018. Universal test and treat and the HIV epidemic in rural South Africa: a phase 4, open-label, community cluster randomised trial. Lancet HIV 5: e116-e125.

6. Churchyard GJ, Mametja LD, Mvusi L, Ndjeka N, Hesseling AC, Reid A, Babatunde S, Pillay Y, 2014. Tuberculosis control in South Africa: successes, challenges and recommendations. $S$ Afr Med J 104 (3 Suppl 1): 244-248.
7. Courtwright A, Turner AN, 2010. Tuberculosis and stigmatization: pathways and interventions. Public Health Rep 125 (Suppl 4): 34-42.

8. Møller V, Erstad I, 2007. Stigma associated with tuberculosis in a time of HIV/AIDS: narratives from the eastern cape, South Africa. South Afr Rev Sociol 38: 103-119.

9. Link BG, Phelan JC, 2006. Stigma and its public health implications. Lancet 367: 528-529.

10. Thomas BE, Shanmugam $P$, Malaisamy M, Ovung S, Suresh $C$, Subbaraman R, Adinarayanan S, Nagarajan K, 2016. Psychosocio-economic issues challenging multidrug resistant tuberculosis patients: a systematic review. PLoS One 11: e0147397.

11. Rood EJJ, Mergenthaler C, Bakker MI, Redwood L, Mitchell EMH, 2017. Using 15 DHS surveys to study epidemiological correlates of TB courtesy stigma and health-seeking behaviour. Int $J$ Tuberc Lung Dis 21: 60-68.

12. Skinner D, Claassens M, 2016. It's complicated: why do tuberculosis patients not initiate or stay adherent to treatment? A qualitative study from South Africa. BMC Infect Dis 16: 712.

13. Munro SA, Lewin SA, Smith HJ, Engel ME, Fretheim A, Volmink J, 2007. Patient adherence to tuberculosis treatment: a systematic review of qualitative research. PLoS Med 4: e238.

14. Van Rie A, Sengupta S, Pungrassami $P$, Balthip Q, Choonuan S, Kasetjaroen Y, Strauss RP, Chongsuvivatwong V, 2008. Measuring stigma associated with tuberculosis and HIV/AIDS in southern Thailand: exploratory and confirmatory factor analyses of two new scales. Trop Med Int Health 13: 21-30.

15. Jittimanee SX, Nateniyom S, Kittikraisak W, Burapat C, Akksilp S, Chumpathat N, Sirinak C, Sattayawuthipong W, Varma JK, 2009. Social stigma and knowledge of tuberculosis and HIV among patients with both diseases in Thailand. PLoS One 4: e6360.

16. Chileshe M, Bond VA, 2010. Barriers and outcomes: TB patients co-infected with HIV accessing antiretroviral therapy in rural Zambia. AIDS Care 22 (Suppl 1): 51-59.

17. Deribew A, Hailemichael Y, Tesfaye M, Desalegn D, Wogi A, Daba S, 2010. The synergy between TB and HIV co-infection on perceived stigma in Ethiopia. BMC Res Notes 3: 249.

18. Eastwood SV, Hill PC, 2004. A gender-focused qualitative study of barriers to accessing tuberculosis treatment in the Gambia, West Africa. Int J Tuberc Lung Dis 8: 70-75.

19. Lawn SD, 2000. Tuberculosis in Ghana: social stigma and compliance with treatment. Int J Tuberc Lung Dis 4: 1190-1191.

20. Rajeswari R, Muniyandi M, Balasubramanian R, Narayanan PR, 2005. Perceptions of tuberculosis patients about their physical, mental and social well-being: a field report from south India. Soc Sci Med 60: 1845-1853.

21. Morris MD, Quezada L, Bhat P, Moser K, Smith J, Perez H, Laniado-Laborin R, Estrada-Guzman J, Rodwell TC, 2013. Social, economic, and psychological impacts of MDR-TB treatment in Tijuana, Mexico: a patient's perspective. Int $J$ Tuberc Lung Dis 17: 954-960.

22. Baral SC, Aryal Y, Bhattrai R, King R, Newell JN, 2014. The importance of providing counselling and financial support to patients receiving treatment for multi-drug resistant TB: mixed method qualitative and pilot intervention studies. BMC Public Health 14: 46.

23. Baral SC, Karki DK, Newell JN, 2007. Causes of stigma and discrimination associated with tuberculosis in Nepal: a qualitative study. BMC Public Health 7: 211.

24. Khan A, Walley J, Newell J, Imdad N, 2000. Tuberculosis in Pakistan: socio-cultural constraints and opportunities in treatment. Soc Sci Med 50: 247-254.

25. Stringer B, Lowton K, Tillashaikhov M, Parpieva N, Ulmasova D, du Cros P, Hasker E, Sergeeva N, 2016. 'They prefer hidden treatment': anti-tuberculosis drug-taking practices and drug regulation in Karakalpakstan. Int $J$ Tuberc Lung Dis 20: 1084-1090.

26. Shah NS et al., 2017. Transmission of extensively drug-resistant tuberculosis in South Africa. N Engl J Med 376: 243-253.

27. Straetemans M, Glaziou P, Bierrenbach AL, Sismanidis $C$, van der Werf MJ, 2011. Assessing tuberculosis case fatality ratio: a meta-analysis. PLoS One 6: e20755.

28. Seedat S, Williams DR, Herman AA, Moomal H, Williams SL, Jackson PB, Myer L, Stein DJ, 2009. Mental health service use 
among South Africans for mood, anxiety and substance use disorders. S Afr Med J 99: 346-352.

29. Clement S, Schauman O, Graham T, Maggioni F, Evans-Lacko S, Bezborodovs N, Morgan C, Rüsch N, Brown JSL, Thornicroft G, 2015. What is the impact of mental health-related stigma on help-seeking? A systematic review of quantitative and qualitative studies. Psychol Med 45: 11-27.

30. Herman AA, Stein DJ, Seedat S, Heeringa SG, Moomal H, Williams DR, 2009. The South African stress and health (SASH) study: 12-month and lifetime prevalence of common mental disorders. S Afr Med J 9: 339-344.

31. Do AN, Rosenberg ES, Sullivan PS, Beer L, Strine TW, Schulden JD, Fagan JL, Freedman MS, Skarbinski J, 2014. Excess burden of depression among HIV-infected persons receiving medical care in the United States: data from the medical monitoring project and the behavioral risk factor surveillance system. PLoS One 9: e92842.

32. Koyanagi A, Vancampfort D, Carvalho AF, DeVylder JE, Haro JM, Pizzol D, Veronese N, Stubbs B, 2017. Depression comorbid with tuberculosis and its impact on health status: crosssectional analysis of community-based data from 48 low- and middle-income countries. BMC Med 15: 209.

33. Singh JA, Upshur R, Padayatchi N, 2007. XDR-TB in South Africa: no time for denial or complacency. PLoS Med 4: e50.

34. Gandhi NR, Andrews JR, Brust JC, Montreuil R, Weissman D, Heo M, Moll AP, Friedland GH, Shah NS, 2012. Risk factors for mortality among MDR- and XDR-TB patients in a high HIV prevalence setting. Int $J$ Tuberc Lung Dis 16: 90-97.

35. O'Donnell MR et al., 2010. High incidence of hospital admissions with multidrug-resistant and extensively drug-resistant tuberculosis among South African health care workers. Ann Intern Med 153: 516-522.

36. Diseases NIfC, 2016. South African Tuberculosis Drug Resistance Survey 2012-2014. Johannesburg, South Africa: National Institute for Communicable Diseases.

37. Daftary A, Padayatchi N, 2012. Social constraints to TB/HIV healthcare: accounts from coinfected patients in South Africa. AIDS Care 24: 1480-1486.
38. Sheehan DV et al., 1998. The Mini-International Neuropsychiatric Interview (M.I.N.I.): the development and validation of a structured diagnostic psychiatric interview for DSM-IV and ICD-10. J Clin Psychiatry 59 (Suppl 20): 22-33; quiz 34-57.

39. Gray AJ, 2002. Stigma in psychiatry. J R Soc Med 95: 72-76.

40. Hayes-Larson E, Hirsch-Moverman Y, Saito S, Frederix K, Pitt B, Maama-Maime L, Howard AA, 2017. Depressive symptoms and hazardous/harmful alcohol use are prevalent and correlate with stigma among TB-HIV patients in Lesotho. Int $J$ Tuberc Lung Dis 21: 34-41.

41. Duko B, Gebeyehu A, Ayano G, 2015. Prevalence and correlates of depression and anxiety among patients with tuberculosis at WolaitaSodo University Hospital and Sodo Health Center, WolaitaSodo, south Ethiopia, cross sectional study. BMC Psychiatry 15: 214.

42. Tomita A, Garrett N, Werner L, Burns JK, Ngcobo N, Zuma N, Mlisana K, van Loggerenberg F, Abdool Karim SS, 2014. Impact of antiretroviral therapy on health-related quality of life among South African women in the CAPRISA 002 acute infection study. AIDS Behav 18: 1801-1807.

43. Tomita A, Garrett N, Werner L, Burns JK, Mpanza L, Mlisana K, van Loggerenberg F, Abdool Karim SS, 2013. Health-related quality of life dynamics of HIV-positive South African women up to ART initiation: evidence from the CAPRISA 002 acute infection cohort study. AIDS Behav 18: 1114-1123.

44. Tomita A, Ramlall S, Naidu T, Mthembu SS, Padayatchi N, Burns JK, 2019. Major depression and household food insecurity among individuals with multidrug-resistant tuberculosis (MDRTB) in South Africa. Soc Psychiatry Psychiatr Epidemiol 54: 387-393.

45. Parker R, Aggleton P, 2003. HIV and AIDS-related stigma and discrimination: a conceptual framework and implications for action. Soc Sci Med 57: 13-24.

46. Tomita A, Ramlall S, Naidu T, Mthembu SS, Padayatchi N, Burns $\mathrm{JK}, 2019$. Neurocognitive impairment risk among individuals with multiple drug-resistant tuberculosis and human immunodeficiency virus coinfection: implications for systematic linkage to and retention of care in tuberculosis/human immunodeficiency virus treatment. J Nervous Ment Dis 207: 307-310. 